\title{
ALGUNOS CASOS DE APLASIA VAGINAL
}

\author{
Doctor Humberto H. Correa
}

Aunque considero importante el hacer un resumen de la embriología femenina como encabezamiento de esta presentación, solamente haré resaltar el hecho de que las anomalías de que vamos a tratar son debidas:

$1^{\text {o }}$ A falta de fusión de los conductos de Muller: como en los casos de útero doble, didelfo, septo, uni c o rne, etc.

$2^{\circ}$ A falta de tunelización de dichos conductos, la cual puede estar situada en la parte inferior de la vagina, limitada a un solo sector o a toda su extensión; a nivel del útero o a nivel de las trompas, $y$

$3^{o ̣}$ A fállas del desarrollo del seno urogenital.

Primer caso: Historia clínica número 22.900, del hospital de la Samaritana.

Se trata de una paciente de 22 años. Casada. Somáticamente bien conformada; senos de desarrollo normal; distribución del vello y grasa de tipo femeninos.

El meato urinario es muy amplio, permite el paso del dedo índice. Se aprecia ausencia de vagina. Al tacto rectal se encuentra una pequeña ma- sa dura, la cual da la sensación de corresponder a un útero rudimentario.

La paciente no aceptó la laparatomía de precisión.

Procedí a construír una neovagina por la técnica de Pellazzo la cual, en síntesis, consiste en practicar una incisión en $\mathrm{T}$ en la mucosa del introito vaginal para obtener colgajos de los pequeños y grandes labios, construír una cavidad en el espacio recto-vesical seccionando los tejidos de la línea media y sostener los colgajos de mucosa obtenidos para aplicarlos al túnel formado. Al final se taponó la cavidad con una gasa humedecida en aceite, la cual se extrajo a los cuatro días y se reemplazó con un molde de aluminio, el cual se dejó a permanencia por quince días.

La paciente salió del Hospital a los 20 días, estando bien cicatrizada las heridas, aunque existía dolor al tacto. Al cabo de tres meses sus relaciones sexuales eran normales. La vagina tenía en este control una longitud de 8 centímetros. Posteriormente no ha vuelto a controles.

El siguiente caso corresponde a la historia número 203.094, del Hospital de la Samaritana de Bogotá. 
Se trata de una paciente de 16 años, que consultaba por cólicos cíclicos localizados en el hipogastrio, que habían venido intensificándose desde ios 12 años de edad, sin haber menstruado hasta la fecha. Al examen de sus genitales nos encontramos que presentaba:

Ginecológico: Implantación pilosa en el monte de venus, normal; vulva de características normales; himen $\mathrm{ru} \mathrm{d}$ imentarios; foseta navicular excavada.

Tacto rectal, no se aprecia vagina, no hay hematocolpo; cuerpo de matriz en sinistro posición, discretamente globoso y duro; no se aprecian claramente estructuras correspondientes a cuello uterino.

Impresión diagnóstica: Criptomenorrea por atresia de vagina. Fdo.), Doctores Correa, Vergara, Luna.

Se propone plastia de vagina y exploración por laparotomía. El 28 de junio se lleva a cabo el acto programado.

Curujano: doctores Luna Uribe y Correa.

Ayudante: doctor Chaparro.

Anestesista: doctor Villalobos.

Anestesia: raquídea, seguida de anestesia general.

Tiempo vaginal: Se procede a construír la neovagina por el método de Sheares. Incisión en raqueta alrededor de la foseta navicular con mango posterior sobre el periné. Disección del colgajo de mucosa a cada lado de la línea media y desprendimiento en el centro, para que dicho colgajo permanezca unido a la piel del periné. Constitución de dos túneles a cada lado de la línea media en el espacio recto-vesical con dilatadores, hasta una profundidad aproximada de 10 centímetros y ampliación de los túneles por medio de los dilatadores de Hegar hasta el número 18. Entre pinzas se secciona el tabique mediano, previo paso de sonda uretral y tacto rectal para proteger la uretra y el recto, respectivamente. Hemostasis de la zona sangrante en el tabique seccionado y de la cavidad de la neovagina. Fijación del colgajo de mucosa, previamente preparado, a la pared posterior vaginal con puntos separados de catgut 000. Exploración de neovagina con espéculo vaginal, no encontrándose estructura que recuerde el cuello uterino. Abertura del peritoneo, observándose exteriorización de sangre antigua.

Al final se dejó molde vaginal de material acrílico, el cual se retiró en el postoperatorio a los 21 días, bajo anestesia. Se revisó la cavidad de la neova gina, encontrándose en condiciones satisfactorias; las paredes eran lisas y brillantes en toda su extensión, y existía epitelización de la pared posterior hasta el tercio medio; en el fondo de la cavidad existía una saliente de tejido de granulación. El tubo de polietileno dejado en la operación se había salido hacia el sexto día postoperatorio. Se introdujo nuevamente el molde vaginal, el cual, desde este momento en adelante, sería retirado diariamente con motivo de la micción o de la evacuación intestina! de la paciente, lubricándolo para su introducción con un ungüento a base de estrógenos.

De allí en adelante, debido a problemas en la aplicación del molde vagi- 
nal, la vagina sufrió estenosis del tercio superior, las cuales fueron tratadas con dilataciones bajo anestesia. Durante los cuatro siguientes meses a la operación, la paciente periódicamente presentó cólicos, pero no se apreció francamente descarga de tipo menstrual.

$\mathrm{Nu}$ vamente, a los nueve meses de la primera intervención, se practicó acto quirúrgico para corregir estenosis del tercio superior de la vagina y nueva laparatomía, en la que se comprobó el satisfactorio estado de los órganos genitales internos.

Se confirmó el abocamiento de la cavidad uterina a la neovagina y se dejó nuevo molde de acrílico con un tallo metálico intrauterino. Un mes después la paciente presentó su primera regla de características normales, sin cólico, y continúa menstruando cíclicamente hasta la fecha. Unicamente es de anotar que existe disminución del calibre del tercio superior de la vagina.

El tercer caso. Corresponde a la historia clínica número 65.707 , del Hospital de la Samaritana, y su resumen es el siguiente:

Se trata de una paciente soltera, de 17 años. Consulta por fuertes cólicos periódicos y raquialgia. Nunca ha tenido menstruaciones.

A la palpación hay una masa globulosa lobulada que llega cerca del ombligo. Al tacto rectal se toca la misma masa. No hay vagina.

Se procede a la laparatomía para drenar esa enorme hematometría y explorar los genitales internos, que estaban de aspecto normal, aunque las trompas estaban engrosadas por el reflujo de sangre.

Algunas semanas después se le practicó la reconstrucción de la neovagina con injertos, sacados del musio y se colocaron sobre un molde del aluminio que se introdujo hasta tener contacto con el cuello uterino.

Este molde permaneció en su sitio dos meses, y los injertos prendieron casi en su totalidad, menos en el fondo de la vagina, el cual comenzó a botonear y a ocluír el cuello uterino lentamente, hasta producirse nuevamente los cólicos.

Hubo necesidad de reoperarla dos veces más para colocarle el tallo metálico de Iribarne y un molde metálico en el fondo de la vagina, con permanencia de un mes más.

El resultado fue muy satisfactorio, y la paciente siguió menstruando normalmente.

Continúa en controles periódicos. Seis años después de esta última operación, contrajo matrimonio, y dos meses más tarde presentó su última regla, el 25 de abril de 1963; al asistir a consulta se comprobó la existencia de un embarazo; actualmente cursa el octavo mes de gestación, existiendo una situación de pelvis del feto.

En estos momentos está hospitalizada en La Samaritana para extirparle un fibroadenoma del seno, el cual está ocasiondo molestias dolorosas.

Como conclusión que se desprende de estas pocas experiencias tenemos el 
hecho de que los métodos que se han sible, una comunicación entre la neoideado para la práctica de neovagina vagina y el útero, salvo el caso de que dan buenos resultados. se trate de úteros no funcionantes, co-

Quiero hacer énfasis de que es immo es el relatado en el primer lugar portante obtener y mantener, en lo po- de esta comunicación. 